\title{
GASTROINTESTINAL PARASITES OF DOMESTICATED DUCK (Anas platyrhynchos LINNAEUS, 1758) IN CHANDRAGIRI MUNICIPALITY, KATHMANDU, NEPAL
}

\author{
Shrestha, D. ${ }^{1}$, Subedi, J. R. ${ }^{1 *}$ and Chhetri, B. ${ }^{2}$ \\ ${ }^{1}$ Central Department of Zoology, Tribhuvan University, Kirtipur, Kathmandu, Nepal \\ ${ }^{2}$ Amrit Campus, Tribhuvan University, Lainchaur, Kathmandu, Nepal \\ "E-mail of corresponding author: janzoology@gmail.com \\ (Received: $11^{\text {th }}$ October, 2019; Accepted: $18^{\text {th }}$ April, 2020)
}

\section{ABSTRACT}

\begin{abstract}
Intestinal parasitosis is one of the chief causes of health problems associated with domesticated and free-range ducks particularly in developing countries. Among the various health problems amoebiasis and helminthic infection are still significant among ducks (Anas platyrhynchos Linnaeus, 1758) in Nepal. We report the status of intestinal parasitosis, particularly the prevalence and associated risk factors of gastrointestinal parasites of ducks reared in three different locations (Bishnu-Devi, Kanchan-Basti and Balambu) of Chandragiri Municipality from November 2016 to February 2017 using opportunistic random method. A total of 120 faecal samples collected in clean, dry and screw-capped plastic containers from six different locations were examined for the presence of parasites using formol-ether concentration method and modified Ziehl Neelsen staining technique, sodium chloride floatation and zinc sulphate sedimentation methods. Overall parasite positive rate was $81.67 \%$ $(98 / 120)$. Positive rate of nematodes was highest $(74.49 \% ; 73 / 98)$ followed by cestodes $(52.04 \% ; 51 / 9)$ and protozoans $(41.84 \%$; 41/98) $(\mathrm{P}<0.05)$. A total of 78 (65.00\%) samples showed single infections and $20(16.67 \%)$ samples showed mixed infection $\left(\chi^{2}=5.55 ; \mathrm{P}<0.05\right)$. Statistical analysis indicated that locations were insignificantly associated with the infection by gastrointestinal tract parasites in the study areas. A total of eight (8) genera of parasites were identified which include two genera of protozoa, five genera of nematodes and one genera of cestodes. Of these, Ascaridia galli (21.67\%) was found to have the highest prevalence and Isospora sp. $(6.67 \%)$ to be the lowest. Gastrointestinal tract parasites were the major biological constraints contributing to the low productivity of ducks and hampered the economic benefits obtained from the sector. Improvement of biosecurity measures for household duck farms through educating and motivating household farmers could help mitigate the effects of parasitic infection on production.
\end{abstract}

Keywords: Duck, Nematode, Cestode, Kathmandu, Chandragiri

\section{INTRODUCTION}

Domestic ducks (Anas platyrbynchas Linnaeus, 1758) play a major role in rural economy in the form of meat and egg. Different types of fowl are reared in Nepal which includes chicken, ducks, turkeys and nowadays, ostriches. Domestic duck is one of the most common and widespread domestic animals $s_{2}$ with a total population of about 700 million. The majority of these, more than 500 million, are in Asia (FAO, 2014). According to the Ministry of Agriculture and Cooperatives, Kathmandu, Nepal; there are more than 378050 ducks in Nepal. Geographically, 72.5 percent are located in the Terai followed by 24.8 percent in the Hills and $2.7 \%$ in the Mountains. In terms of administrative division, the distribution of ducks is highest (37.4\%) in the Eastern Development Region followed by the Central (30\%), Western (22\%), Mid-western (7.5\%) and Far-Western $(2.8 \%)$ regions $(F A O, 2014)$. It is one of the most common and domesticated bird species after chicken in the world.

Humans keep ducks primarily for eggs and meat (FAO, 2014). Other products from ducks, which can be sold, include down, feathers, and fattened livers (van der Meulen and den Dikken, 2004). Geographical location, subtropical climatic condition, water- logged and low areas of the country are suitable habitats for rearing duck but these factors also favour growth, multiplication, development, survival and spread of parasites (Farjana et al., 2008). Parasitic infestation cause diseases in ducks and affect their productivity and growth. Parasitic infection in duck is the major problem in Nepal, which leads to economic loss to the country. Domestic fowls are more often infected due to unhygienic management practices, malnutrition, lack of veterinary supervision, and the complicated life cycle of the parasites (Muhairwa et al., 2007). Gastro- intestinal parasites are however the most prevalent and most 
devastating parasites affecting duck productivity (Mohammed, 2009).

In village, ducks are raised mainly under the free range (scavenging) with partial or no housing and this predisposes almost all ducks to suffer from parasitic diseases (Farjana et al., 2008), such as helminthiasis (Sultanov et al., 1970; Megacheva, 1981; Sovetnikov, 1984). Protozoan parasites like Entamoeba gallinarum, Cryptosporidium species are also responsible for causing disease to different organs and tissues of ducks (Mousa, 2000). Duck infected with parasites show retarded growth, decreased egg production, reduced weight gain, significant haemoglobin depression (Mohammed, 2009), villous atrophy, catarrhal enteritis, granuloma formation in duodenum, desquamation of villi and submucosal gland congestion, inflammatory reaction and vacuolation of epithelial cells (Mahmoud et al., 2011).

Different types of helminth parasites infect the duck flocks. Worms find cozy places to stay in the crop, gizzard, intestine, caecum, windpipe and even the eyelids (Gauthier et al., 2013). On the basis of their site of location helminths are of different types, the worm which are found in caecum of large intestine are called caecal worms (Heterakis spp.), worms which are found in eye are called eye worm (Oxyspirura mansoni), Gape worms are found in trachea (Syngamus trachea) (Gauthier et al., 2013). These worms are also called "redworm" or "forked-worm" and birds infected with gapeworm show "open mouth breathing characteristics". Roundworm (Ascaridia spp.) and tapeworms (Raillietina spp.) are found in intestine while threadworm (Capillaria spp.) is found in crop or oesophagus (Janquera, 2017). The eggs and immature stages of many parasitic worms can live outside of the duck host for a long time, possibly several years, whereas some parasitic worms spend part of their life cycle in other creatures such as earthworms, insects, slugs or snails. Domestic fowls such as chicken and duck pick up worms by eating dirt or litter contaminated with worms' eggs or by eating small creatures carrying immature stages of worm or snail (Janquera, 2017). Ducks are in continuous contact with cultivated lands, irrigation canals where they are in frequent contact with suitable intermediate hosts of parasites. This study was carried out to document the prevalence rate of gastrointestinal parasite infection in ducks.

\section{MATERIALS AND METHODS Study Area}

The study was carried out in three different places including Bishnu-Devi, Kanchan-Basti and Balmbu of Chandragiri Municipality (Figure 1). The capital city Kathmandu is approximately five to nine $\mathrm{km}$ away from study area. It is best known for its rich cultural heritage particularly its tradition of arts and crafts. At the time of 2011 Nepal census it had a population of 87553 . Chandragiri has an area of $43.9 \mathrm{~km}^{2}$. It is situated at $27^{\circ} 41^{\prime} 25^{\prime \prime} \mathrm{N}$ Latitude, $85^{\circ} 13^{\prime} 13^{\prime \prime} \mathrm{E}$ Longitude and 1425 meter above sea level (masl) to 2551 masl altitude. Climate of this area is relatively low temperature and precipitation that are evenly distributed throughout the year. There are a total of 1,738,491 domesticated ducks in Kathmandu district (FAO, 2014). Of these, 17,880 are reared in backyard and 1,720,611 are reared commercially as poultry ducks. 

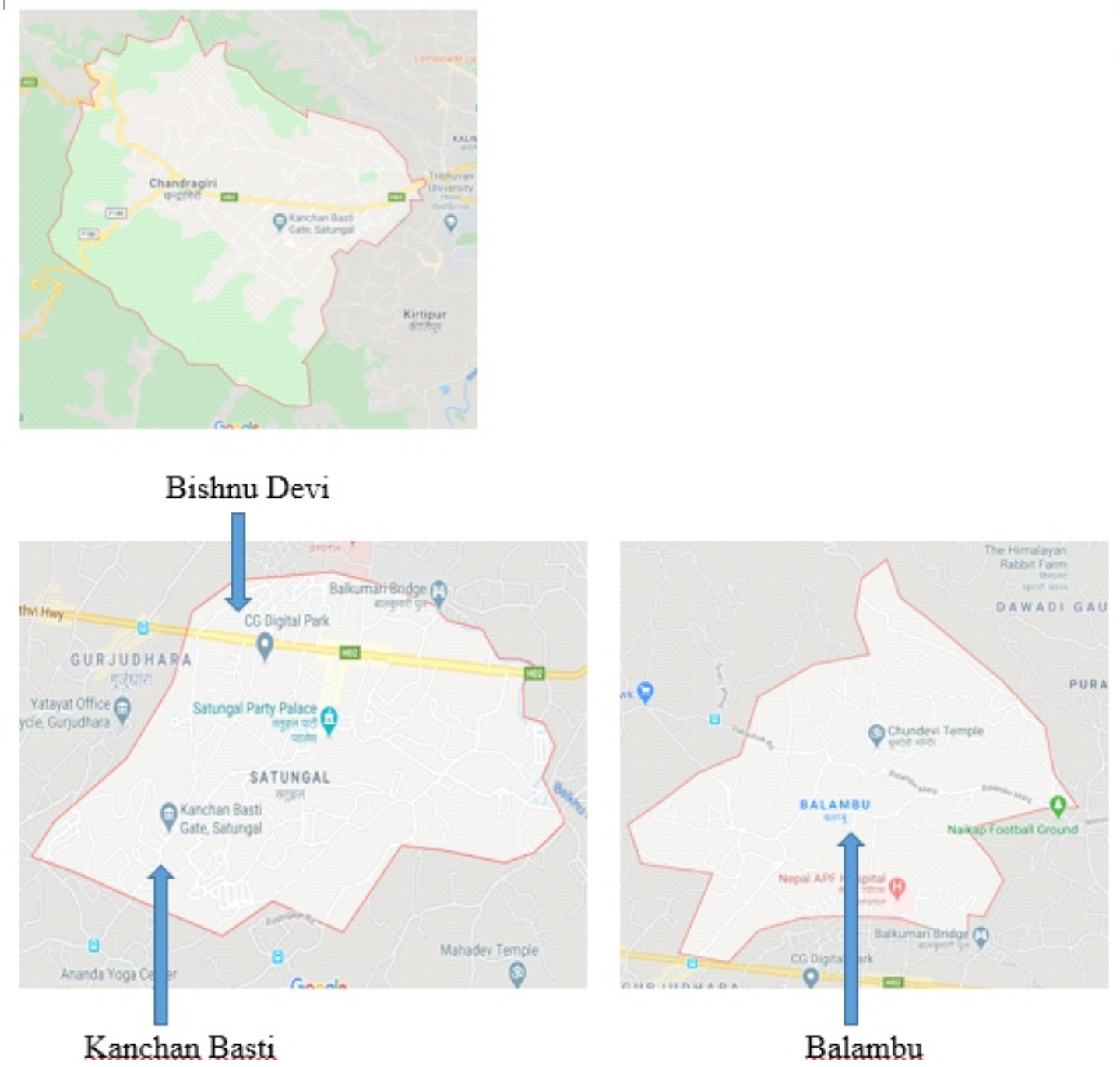

Figure 1: Study Areas in Chandragiri Municipality.

Sample Collection Preservation and Examination

A total of 120 samples (40 samples from each study area) were collected from Bishnu-Devi, Kanchan-Basti and Balambu of Chandragiri Municipality, Kathmandu district from February to November 2017. The faecal samples were collected in sterile vials containing $70 \%$ ethanol with the help of wooden stick. The $70 \%$ alcohol was preservative that helped in maintaining morphology of protozoan parasites and prevent further development of helminth eggs and larvae. The samples were brought to Central Department of Zoology, Kirtipur, Kathmandu. For this study, prevalence was measured as the percentage of host individuals infected with a particular parasite (Margolis et al. 1982, Bush et al. 1997). Depending on the convenience, differential floatation method, sedimentation method and direct smear method were used for the examination of samples.

For differential floatation method, saturated salt solution of specific gravity 1.2 was prepared by allowing an excess of common salt $(\mathrm{NaCl})$ to boil in a basin until a scum was formed on the surface. It was cooled and stored in a bottle leaving an excess of undissolved salt at the bottom. Four gram of faecal material was taken in a test tube and a few drops of salt solution was added (Hansen $e t$ al., 1994). It was then stirred with a glass rod or a small piece of stick so as to make an even emulsion. After that, more salt solution (15 to 20 $\mathrm{ml}$ according to the capacity of the test tube) was added till the test tube was nearly full, stirring was continued through the process. Any coarse matter, 
which floats on top, were removed without fear of removing any egg, as egg takes a long time (20 to 30 minutes) to come to the surface of the fluid. At this stage the test tube was placed on the level surface and the final filling of the test tube was done by means of a dropper until a convex meniscus was formed. A glass slide was carefully laid on the top of the test tube so that its center is in contact with the fluid. The preparation was allowed to stand for 20 to 30 minutes, after which the glass slide was quickly lifted, turned over smoothly so as to avoid spilling of the liquid and was examined under the microscope (Soulsby, 1982 and Chatterjee, 2009).

Sedimentation technique was used for the detection of nematodes eggs. It provided good results as the egg of nematodes is a bit heavier than the other eggs and deposited in the bottom (Veterinary lab techniques, 2003). For this technique $3 \mathrm{~g}$ of stool sample was taken in a beaker, $42 \mathrm{ml}$. of water was added and ground with the help of mortar and pestle. The sample was filtered with a tea strainer and filtered samples were poured in a plastic test tube. The tube was taken out and upper water was removed with the help of a pipette. $\mathrm{NaCl}$ solution was filled in the tube and again centrifuged at $1000 \mathrm{rpm}$ for $5 \mathrm{~min}$. A drop of deposited materials was taken out from the test tube with the pipette and placed on the slide, followed by addition of 3-4 drops of methylene blue into it, and examined under the microscope at X 10 and X 40 magnification.
For direct smear method, small amount of faeces was placed on a slide. A drop of normal saline or Lugol's solution was added to the faeces and mixed thoroughly. Since we were looking for the helminth eggs, larvae and cysts, Lugol's solution or normal saline was used. Then the faecal materials were covered with cover slip. The cover slip was moved around until it laid flat. The smear film was made thin so that the light from the microscope was able to pass through the sample in order for us to examine it. The slides were examined at X10 and X40 magnification. (Soulsby, 1982 and Chatterjee, 2009).

\section{Statistical Analysis}

The collected data were coded and entered into Microsoft Excel spread sheet. Data were statistically analyzed using Pearson's Chi-square test with Yates' continuity correction, performed by "R", version 3.3.1 software packages (R Core Team, 2017). Percentage was used to calculate prevalence. Data were statistically analyzed using Chi-square. In all cases 95\% confidence interval (CI) and $\mathrm{p}<0.05$ was considered for statistically significant difference.

\section{RESULTS}

Among 120 samples collected from the field, 98 samples were found to be positive with single or multiple infection of gastro-intestinal parasites (Figure 2).

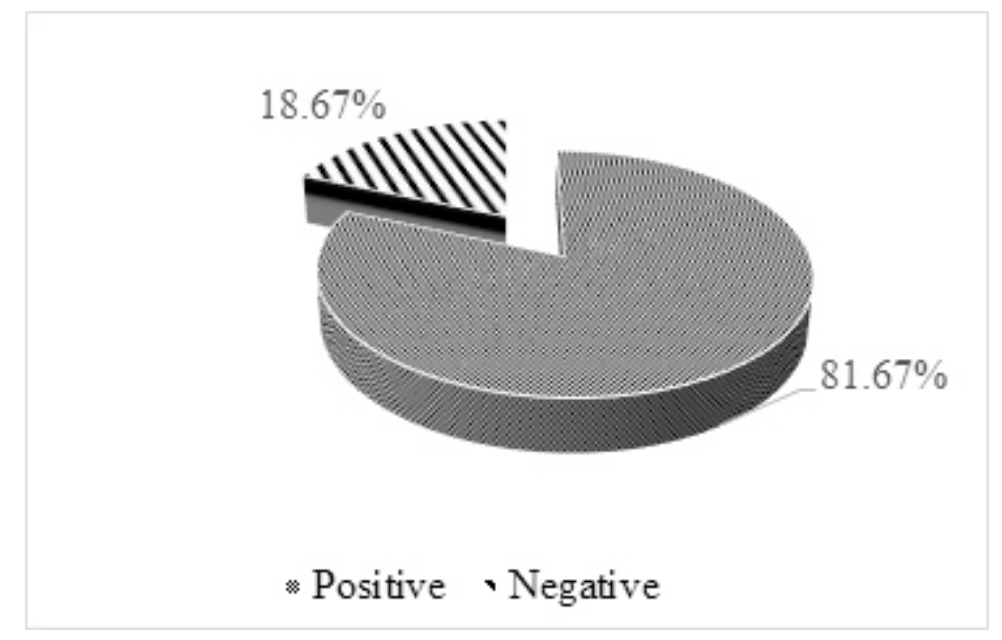

Figure 2: Overall Prevalence of Gastrointestinal Parasites. 
A total of six helminths and two protozoan parasites were isolated from the faecal samples and identified. The identified helminths were Ascaridia galli, Heterakis sp., Capillaria sp., Trichurus sp., Raillietina sp. and Strongyloides sp. The intestinal protozoan parasites were Eimeria sp. and Isospora sp. The most frequently observed was Ascaridia galli $(21.67 \%)$ followed by Capillaria sp. (20\%), Hetarakis sp. (17.50\%), Trichurus sp. (15.83\%), Strongyloides sp. $(12.50 \%)$ and Raillietina sp. $(10.83 \%)$ for helminths parasites. For intestinal protozoan parasites Eimeria sp. (15\%), showed the highest prevalence than Isospora sp. (6.67\%).

Table 1: Species-wise Prevalence Rate (\%), $\mathrm{n}=120$

\begin{tabular}{lcccc}
\hline Name of parasite & Frequency & Absolute Frequency (\%) & No. of -ve samples & P-value \\
\hline Ascaridia galli & 26 & 26.53 & 72 & \\
Capillaria sp. & 24 & 24.49 & 74 & $2.2 \times 10^{-16}$ \\
Hetarakis sp. & 21 & 21.43 & 77 & \\
Trichurus sp. & 19 & 19.39 & 89 & \\
Eimeria sp. & 18 & 18.37 & & \\
\hline \hline Total & 98 & & & \\
\hline
\end{tabular}

Key: Statistically, there was a significant difference in the prevalence of helminth and protozoanspecies $(\chi 2=647.51, \mathrm{p}<0.05)$.

Among positive samples, the highest occurrence were nematodes $(105 / 120)$ followed by protozoan $(26 / 120)$ and cestodes (13/120). Overall, there was high prevalence of intestinal parasites in Bishnu Devi than Kanchan Basti and Balambu study areas. In Bishnu Devi, there was the highest prevalence of Ascaridia galli (32.50\%) and lowest prevalence of Raillietina sp. $(7.50 \%)$ and Hetarakis sp. $(7.50 \%)$. Likewise, in Kanchan Basti, there was highest prevalence of Hetarakis sp. (30\%) and lowest prevalence of Strongyloides sp. (5\%). Similarly, in Balambu, there was highest prevalence of Ascaridiagalli (17.5\%) and the lowest prevalence of Isospora sp. (2.5\%) and Trichuris sp. $(2.5 \%)$.

Table 2: Class-wise Comparative Prevalence of Parasite Classes in Different Locations.

\begin{tabular}{|c|c|c|c|c|c|}
\hline Class & Parasite Name & $\begin{array}{l}\text { Bishnu-Devi } \\
(\mathrm{N}=40)\end{array}$ & $\begin{array}{l}\text { Kanchan- } \\
\text { Basti } \\
(\mathrm{N}=40)\end{array}$ & $\begin{array}{l}\text { Balambu } \\
(\mathrm{N}=40)\end{array}$ & $P$-value \\
\hline \multirow[t]{2}{*}{ Coccidia } & Eimeria sp. & 8 & 8 & 4 & \multirow{8}{*}{$2.2 \times 10^{-6}$} \\
\hline & Isospora sp. & 4 & 4 & 1 & \\
\hline Cestoda & Raillietina sp. & 3 & 3 & 4 & \\
\hline \multirow[t]{5}{*}{ Nematoda } & Capillaria sp. & 8 & 8 & 5 & \\
\hline & Hetarakis sp. & 3 & 3 & 6 & \\
\hline & Trichuris sp. & 9 & 9 & 1 & \\
\hline & Strongyloides sp. & 9 & 9 & 4 & \\
\hline & Ascaridia galli & 13 & 13 & 7 & \\
\hline Total & & 57 & 55 & 32 & \\
\hline
\end{tabular}

Key: Statistically, there was a significant difference in the prevalence of parasitic classes among different study areas $\left(\chi^{2}=992, \mathrm{p}<0.05\right)$. 
The highest prevalence of gastrointestinal parasites was revealed in Bishnu Devi location $(95.55 \%)$ followed by Kanchan Basti $(82.50 \%)$ and Balambu $(67.50 \%)$ study areas. Out of total examined ducks, $20(16.67 \%)$ were found to harbour mixed infections and $78(65.00 \%)$ were found to harbour single infections.

Table 3: Location-wise Prevalence of Single and Mixed Infection.

\begin{tabular}{|c|c|c|c|c|}
\hline \multirow[t]{2}{*}{ Location } & \multirow[t]{2}{*}{ No. of ducks examined } & \multicolumn{2}{|c|}{ Infection Type } & P-Value \\
\hline & & Mixed Infection & $\begin{array}{l}\text { Single } \\
\text { Infection }\end{array}$ & \\
\hline Bishnu Devi & 40 & 8 & 30 & \\
\hline Kanchan Basti & 40 & 7 & 26 & 0.08 \\
\hline Balambu & 40 & 6 & 21 & \\
\hline Total & 120 & 20 & 78 & \\
\hline
\end{tabular}

Key: Statistically, there was a significant difference in the prevalence of location wise distribution of single and mixed infection of gastrointestinal parasites $\left(\chi^{2}=16.41, \quad \mathrm{p}<0.05\right)$.

\section{DISCUSSION}

Among the total of 120 samples, 98 samples were found to be positive with single or multiple infection of 8 genera of gastrointestinal parasites. The present study showed six different helminths and two different intestinal protozoan parasites. The intestinal parasites found in ducks in the study area are common parasites of domestic chickens (Muhairwa et al., 2007). It may be due to the reason that the ducks, wild birds and domestic chickens share the study areas for fending. Furthermore, the ducks shared the same habitat with chicken and also used the same food and water. Therefore, the probability of sharing the common parasitic infections among ducks, chicken and wild birds is high. The high occurrence of parasites in this study area may be due to the duck management system as described by Muhairwa et al. (2007).

According to the system, ducks are exposed to the presence of eggs, oocysts, larvae, segment of helminths and protozoa in the soil during fending. Furthermore, overcrowding of ducks in their habitat enhances the contamination of food, water and the environment through disposal of faeces containing eggs, oocysts and larvae. The optimum temperature, humidity and rainfall conditions favour the survival and spread of gastro-intestinal parasites in the study area which accelerate the high prevalence (Farjana et al., 2004). Similarly, the occurrence of parasite eggs in study area might be due to regular feeding on infected droppings or infected intermediate hosts of the parasites such as beetles, cockroaches, earthworm flies and grasshoppers.

Among the identified gastrointestinal parasites in duck, Ascaridia galli were dominant, which was followed by Trichuris sp., Strongyloides sp., Capillaria sp., Eimeria sp., Isospora sp., Raillietina sp. and Hetarakis sp. in that order. It is probably due to the lack of regular treatment of ducks with antiprotozoan and anti-helminthic drugs in study areas. This assumption can be supported by the presence of 10 species of gastrointestinal parasites from postmortem examinations in a similar study carried out in Pakistan (Yousuf et al., 2009). The present findings contradict the findings of Muhairwa et al. (2007) in free-range ducks in Tanzania; Yoshino et al. (2009) in four families of waterfowl in Japan; Adejinmi et al. (2011) in domestic ducks in southwestern Nigeria; Mahmoud et al. (2011) in duck intestine in Egypt; Hoque et al. (2014) in domestic and wild birds in Bangladesh; Yiqiang et al. (2016) in free-range local ducks in Kenya and Singh and Mohilal (2017) in dispersed species of domestic birds in India.

Among the identified gastrointestinal parasites, Class Nematoda is found to be highest (41.84\%) with five genera followed by Class Cestoda (31\%) with one genus and protozoa $(25 \%)$ with two genera. This outcome might be an indication of the availability of infective stages of the worms in the study area and the ability of the infective stage of the worms to survive outside the host for a long time before it is picked up by the host. Lower 
burden of cestodes and absence of trematodes might be due to the molluscan intermediate hosts which were not available during the sample collection (winter season). This finding is supported by the result of Muhairwa et al. (2007) on the gastrointestinal tracts of free-ranging ducks in Morogoro Municipality, Tanzania. The reasons for the absence of trematodes might be that all species of trematodes are transmitted to the host as metacercaria, a larval resting stage found in fish, amphibians and leech, which were absent in testing period. Moreover, duck from Balumbu were reared inside cages where they were totally out of contact with such intermediate hosts. The nematodes can complete their life cycle without intermediate hosts (Soulsby, 1982) hence, high infection rate of nematodes in Poultry (Sandhu et al., 2009).

Location wise prevalence of gastrointestinal parasite is more in Bishnu devi (95.00\%) followed by Kanchan basti $(82.50 \%)$ and Balambu (37.50\%). The high prevalence of gastrointestinal parasite in Bishnu devi study area may be because ducks were in continuous contact with Bishnu devi river where they were in frequent contact with suitable intermediate hosts of parasites and they were reared in larger flock with pig and fish in traditional, rural scavenging system. The reason for less positive sample for gastrointestinal parasites in ducks of Balambu might be due to the fact that they were dewormed just before the study and were reared separately where there was less chance of contamination and away from source of water and irrigation channels. Overall, there was $67.5 \%$ prevalence of gastrointestinal parasites. This might be due to the use of albendazole, which has only 33\% efficacy against Capillaria sp. up to 21 days and $67 \%$ efficacy against Heterakis sp. up to 21 days.

Prevalence of gastrointestinal parasites is also affected by the route of drug administration as explained by Tucker et al. (2007).

Furthermore, it is thought that the prevalence of gastrointestinal parasites is considerably influenced by the climatic conditions and as far as possible; the evidence for the distribution and prevalence of the diseases is presented by geographical area, roughly corresponding to climatic conditions. Generally, the warm and humid conditions, which prevail in much of South-East Asia, provide good conditions for many gastro intestinal parasites to flourish. Continuous high rainfall throughout the year in parts of the region means that there is no season during which the parasites are not a problem.

Results from countries with climate as that of Nepal like Bangladesh, India, Vietnam, Nigeria and Thailand are similar to the one from the present study. Yousuf et al. (2009) found 81.1\% positive test in ducks of parasite in Bangladesh, which is almost the same as present finding (81.67\%). Adejinmi et al. (2011) found five species of nematodes where Ascaridia galli was the most frequently observed (46.8\%) followed by Heterakis gallinarum (23.4\%) and Capillaria sp. (21.7\%). This is similar to the present findings where Ascaridia galli was the most frequently observed $(21.67 \%)$ followed by Capillaria sp. $(20 \%)$ and Heterakis gallinarum $(17.50 \%)$.

\section{O N C L U S I O N A N D RECOMMENDATIONS}

Almost $81.67 \%$ subjects were recorded as positive cases where helminthes parasitic infection were prevalent than protozoan infection. Altogether 8 genera of parasites were encountered with $A$. galli as the most common helminthes parasite. This shows that gastrointestinal parasitic infection is still a major health problem in ducks. Nematoda had a high prevalence $(74.49 \%$ ) and Coccidia showed least prevalence (41.84\%), whereas, Trematode was absent. Bishnudevi study area harboured (95\%) and Balambu study area harboured comparatively less parasites $(67.50 \%)$. Ducks were more infected with single $(65.00 \%)$ infection than mixed (16.67\%) infection. The study confirmed that ducks were found to be highly susceptible and infested by various gastrointestinal parasites. So, management practices and locations where they are reared can be considered as important factors which influence the prevalence of gastrointestinal parasites. Veterinary health programmes, appropriate prevention and control strategies supported by both government and private sector will be necessary to minimize the gastro-intestinal parasites of ducks. 


\section{CONFLICT OF INTEREST}

None Declared.

\section{ACKNOWLEDGEMENTS}

We are thankful to our honorable former Head of Department Prof. Dr. Ranjana Gupta, Central Department of Zoology, TU., Kirtipur. We would also acknowledge Prof. Dr. Mahendra Maharjan for his assistance in the research work. Lastly, we extend our heartfelt gratitude to all the teachers, friends and staff of Central Department of Zoology for their continuous aspiration and motivation.

\section{REFERENCES}

Adejinmi, J.O. and Oke, M. 2011. Gastrointestinal parasites of domestic ducks (Anas platyrbynchos) in Ibadan Southwestern Nigeria. Asian Journal of Poultry Science, 5: 46-50.

Bush, A.O., Lafferty, K.D., Lotz, J.M. and Shostak, A.W. 1997. Parasitology meets ecology on its own terms: Margolis et al. revisited. Journal of Parasitology, 83: 575-583.

Chatterjee, K.D. 2009. Parasitology: Protozoology and Helminthology. 13th ed. CBS publishers. pp. 260-266.

Food and Agriculture Organization (FAO). 2014. Poultry Sector Nepal. FAO Animal Production and Health Livestock Country Reviews. No. 8. Rome.

Farjana, T., Islam, K.R. and Mondal, M.M.H. 2008. Population density of helminths in ducks: effects of host's age, sex, breed and season. Bangladesh. Journal of Veterinary Medicine, 6(1): 45-51.

Farjana, T., Alim, M.A., Das, P.M. and Mondal, M.M.H., 2004. Helminth infection in ducks at free range and semi intensive farming in two districts of Bangladesh. Bangladesh Veterinary Journal, 38: 125-134.

Gauthier, J. and Ludlow, R.T. 2013. Chicken health for dummies. In Ten Common Misconceptions about Chicken Health and Treatments. $1^{\text {st }}$ ed. 331 pp.

Hansen, J. and Perry, B. 1994. Techniques for parasites assays and identification in fecal samples. In Management of vertisols in SubSaharan Africa, 39: 77-92.

Hoque, M.A., Hassan, M.M., Haque, E., Shaikat, A.H., Khan, S.A., Alim, A., Skerratt, L.F.,
Islam, A., Tun, H.M., Dissanayake, R., Day, T.K., Debnath, N.C. and Yamage, M. 2014. A survey of gastro-intestinal parasite infection in domestic and wild birds in Chittagong and Greater Sylhet, Bangladesh. Preventive Veterinary Medicine, 117(1): 305-312.

Janquera, P. 2017. Parasites of dogs, cats, horses and livestock: Biology and control. Parasitipedia.net.

Margolis, L., Esch, G.W., Olmes, J.C.H, Uris, A.M.K. and Shad, G.A. 1982. The use of ecological terms in parasitology (report of an ad hoc committee of the American Society of Parasitologists). Journal of Parasitology, 68(1): 131-133.

Mahmoud, A., Nasr, E., Mosaad, A.H. and Naoaki, Y. 2011. Prevalence of the enteric parasites of ducks from Behera governorate, Egypt. The Journal of Protozoology Research, 21:36-44.

Muhairwa, A.P., Msoffe, P.L., Ramadhani, S., Mollel, E.L., Mtambo, M.M.A., and Kassuku, A.A. 2007. Prevalence of gastro-intestinal helminths in free-range ducks in morogoro mumcipality, Tanzania. Livestock Research for Rural Development, 19:2-2.

Megacheva, L.D. 1981. Dynamics of nematode infection of ducks and geese and the infection sources on industrial poultry farms. Bulletene, Vsesyuzonogo instituta Gel, minthologii, inn K.I. Skryabina, 30: 56-61.

Mohammed, N.H. 2009. Detection of Cryptosporidium sp. in faeces of ducks in Nineveh governorate. Iraqi Journal of Veterinary Sciences, 23(1): 1-5.

Mousa, A.A.S. 2000. Studies on cryptosporidiosis in ducks in Kafr El-Sheikh province. M.V.SC. Poultry diseases. Faculty of Veterinary Medicine, Tanta University, Egypt.

Muhairwa, A.P., Msoffe, P.L., Ramadhani, S., Mollel, E.L., Mtambo, M.M.A. and Kassuku, A.A. 2007. Prevalence of gastro-intestinal helminths in free-range ducks in Morogoro. Livestock Research for Rural Development, 19(4).

R Core Team. R: A Language and Environment for Statistical Computing. R Foundation 9 
for Statistical Computing, Vienna, Austria. URL https://www.Rproject.org/, 2017.

Sandhu, B.S., Brar, R.S., Brar, A.P.S., Sood, N.K. and Singla, L.D. 2009. Prevalence and pathology of parasitic gastrointestinal infections of poultry in Punjab. Indian Veterinary Journal, 86(12): 1276-1277.

Singh, L.J and Mohilal, N. 2017. Gastrointestinal parasitic infection in diverse species of domestic birds of Manipur, India. Journal of Parasitic Diseases, 41(1): 142-146.

Soulsby, E.J.L. 1982. Helminths, arthropods and protozoa of domesticated animals. 7th Edition, Baillere Tindal, London, pp.763777.

Sovetnikov, V.M. 1984. Helminths of domestic ducks in the Penza region. Biologiya I taksonomiya gelmintov zhivotnykh I cheloveka, 34: 74-77.

Sultanov, M.A., Adysheva, M.M., Sarymsakov, F.S., Muminov, P. and Sabirov, O. 1970. Helminths of geese and ducks. Tashkend, USSR: Izdatel'Stou FAN/Uzbekskovi SSR, 58-90.

Tucker, C.A., Yazwinski, T.A., Reynolds, L., Johnson, Z. and Keating, M., 2007. Determination of the anthelmintic efficacy of Albendazole in the treatment of chickens naturally infected with gastrointestinal helminths. Journal of Applied Poultary Research, 16(3):392-396.

Van der Meulen, S.J. and Den Dikken, G. 2004. Duck keeping in the tropics. In Agrodok 33, Overgaag A. (ed.). Agromisa Foundation, Wageningen, the Netherlands.

Veterinary Laboratory Techniques, 2003. Central Veterinary Laboratory Tripureshwar.

Yiqiang, T., Hui, Z., Kun, L., Yajing, W., Mujeeb, U.R. and Houqiang, L. 2016. Investigation of intestinal parasites infections in free range poultry of Anhui Province, China. Indian Journal of Animal Research, B-471. DOI:10.18805/ijar.10985.

Yoshino, T., Nakamura, S., Endoh, D., Onuma, M., Osa, Y., Teraoka, H., Kuwana, T. and Asakawa, M. 2009. A helminthological survey of four families of waterfowl (Ardeidae, Rallidae, Scolopacidae and Phalaropodidae) from Hokkaido, Japan. Journal of the Yamashina Institute for Ornithology, 41(1): 42-54.

Yousuf, M.A., Das, P.M., Anisuzzaman, M. and Banowary, B. 2009. Gastro-intestinal helminths of ducks: some epidemiologic and pathologic aspects, Journal of the Bangladesh Agricultural University, 7(1): 9197. 